\title{
Article \\ Telemedicine Is an Effective Tool to Monitor Disease Activity in IBD Patients in the COVID-19 Era: A Single Centre Experience Based on Objective Data
}

\author{
Emanuele Sinagra ${ }^{1, *,+}$, Anita Busacca ${ }^{2,+}$, Laura Guida ${ }^{2}$, Lucio Carrozza ${ }^{2}$, Daniele Brinch ${ }^{2} \mathbb{D}$, Federica Crispino ${ }^{2}$, \\ Marcello Maida ${ }^{3}$, Salvatore Battaglia ${ }^{2}$, Ciro Celsa ${ }^{2,3,4}{ }^{\mathbb{D}}$, Calogero Cammà ${ }^{2}$ and Maria Cappello ${ }^{2}$
}

check for

updates

Citation: Sinagra, E.; Busacca, A.; Guida, L.; Carrozza, L.; Brinch, D.; Crispino, F.; Maida, M.; Battaglia, S.; Celsa, C.; Cammà, C.; et al.

Telemedicine Is an Effective Tool to Monitor Disease Activity in IBD Patients in the COVID-19 Era: A Single Centre Experience Based on Objective Data. Gastroenterol. Insights 2022, 13, 117-126. https://doi.org/ 10.3390 /gastroent 13010013

Academic Editors:

Tsvetelina Velikova and

Radislav Nakov

Received: 15 January 2022

Accepted: 1 March 2022

Published: 7 March 2022

Publisher's Note: MDPI stays neutral with regard to jurisdictional claims in published maps and institutional affiliations.

Copyright: (c) 2022 by the authors Licensee MDPI, Basel, Switzerland. This article is an open access article distributed under the terms and conditions of the Creative Commons Attribution (CC BY) license (https:// creativecommons.org/licenses/by/ $4.0 /)$.
1 Gastroenterology and Endoscopy Unit, Fondazione Istituto G. Giglio, Contrada Pietra Pollastra Pis Ciotto, 90015 Cefalù, Italy

2 Gastroenterology and Hepatology Section, PROMISE, University of Palermo, 90127 Palermo, Italy; anitabusacca05@gmail.com (A.B.); laura.guida91@gmail.com (L.G.); lucio.carrozza@gmail.com (L.C.); danielebrinch@gmail.com (D.B.); federica.crispino123@gmail.com (F.C.); salvatore.battaglia91@gmail.com (S.B.); celsaciro@gmail.com (C.C.); carlo.camma@unipa.it (C.C.); marica.cappello61@gmail.com (M.C.)

3 Gastroenterology and Endoscopy Unit, S. Elia-Raimondi Hospital, 93100 Caltanissetta, Italy; marcello.maida@hotmail.it

4 Department of Surgical, Oncological and Oral Sciences (Di.Chir.On.S.), University of Palermo, 90100 Palermo, Italy

* Correspondence: emanuelesinagra83@googlemail.com; Tel.: +39-0-21920712

+ These authors contributed equally to this work.

Abstract: Background: The COVID-19 outbreak has led IBD clinics to adopt a remote monitoring approach in order to guarantee an adequate follow-up of patients with inflammatory bowel disease (IBD) and ensure the rules of social distancing. Aim: The aim of the study was to perform a survey on IBD patients who underwent remote monitoring in our tertiary referral center, to assess adherence, patients' perceptions and satisfaction, and finally their opinions for future monitoring. Furthermore, we evaluated changes in disease activity and Quality of Life (QoL) using validated questionnaires. Methods: Consecutive patients with IBD scheduled for follow-up visits were switched to remote monitoring through e-mail from March 2020 to February 2021. Patients were asked to complete a questionnaire focusing on the following elements of the intervention: (1) self-assessment questions, (2) action plans, and (3) educational messages. Results: Four hundred and twenty four Caucasian patients completed the survey. 233 (55.1\%) were male, 220 (52.0\%) had Crohn's Disease (CD). Median baseline Mayo Score and Harvey Bradshaw Index were 3 and 4, respectively. 9 (2.1\%) patients were referred to the emergency department because of disease flares. $410(96.9 \%)$ patients were satisfied with telemedicine, and 320 (76.5\%) patients reported that they would maintain this approach also after COVID-19 pandemic. Overall, on univariate logistic regression analysis, none of the variables were related to patients' satisfaction or to an improved QoL. The presence of ulcerative colitis was associated with the need for treatment change. Conclusions: Our results suggest that a telemedicine approach is well accepted by patients with IBD and could represent an effective tool in monitoring disease activity. Further controlled studies are warranted to properly assess if telemedicine can replace face-to-face consultations in IBD.

Keywords: inflammatory bowel disease; COVID-19; telemedicine; ulcerative colitis; Crohn's Disease

\section{Introduction}

Inflammatory Bowel Disease (IBD), namely Crohn's Disease (CD), ulcerative colitis (UC), and indeterminate colitis (IC), are chronic idiopathic inflammatory disorders of the gastrointestinal tract [1,2], affecting more than 2 million Europeans and 1.5 million North 
Americans. IBDs are associated with high healthcare resource utilization leading to relevant direct and indirect costs [3].

The aim to integrate new technologies into our practice of medicine led to an increasing interest in the use of telemedicine and remote patient monitoring in the management of chronic diseases [4]. Telehealth is defined by the American Telemedicine Association as "technology-enabled health and care management and delivery systems that extend capacity and access" [4,5]. It includes multiple forms, including remote patient monitoring, tele-health, tele-consultation, and the use of mobile-application-based technology [4]. The most important areas in gastroenterology where telemedicine is used include IBD [6-8], gastrointestinal motility [6,9], and Hepatitis C Virus treatment monitoring [6,10].

The occurrence of human infection with the severe acute respiratory syndrome coronavirus-2 (SARS-CoV-2) in December 2019 in Wuhan, China, and its rapid evolution into the coronavirus 2019 (COVID-19) pandemic in March 2020, markedly stressed healthcare systems [6,11]. Multiple organizations recommended several public health measures such as stay-at-home orders, social distancing, quarantines, and containment in the US and globally $[6,12-14]$. These measures discouraged face-to-face (F2F) encounters that increased infection transmission risk. To guarantee an adequate follow-up, IBD centers worldwide were urged to adopt telemedicine during the general lock-down, as encouraged by the 2nd Interview of the COVID-19 ECCO Taskforce in March $2020[15,16]$.

However, physicians were concerned whether a telemedicine approach could negatively affect the doctor-patient relationship and disease outcomes.

The aim of the study was to perform a survey on IBD patients who underwent remote monitoring in our tertiary referral center to assess adherence, patients' perceptions and satisfaction, and finally their opinions for future monitoring. Furthermore, we evaluated changes in disease activity and Quality of Life $(\mathrm{QoL})$ using validated questionnaires.

\section{Patients and Methods}

Five hundred sixty-five consecutive patients with IBD scheduled for follow-up visits at the IBD Clinic of the Gastroenterology Section, University of Palermo, were switched to remote monitoring via e-mail from March 2020 to February 2021. Indeed, during the COVID-19 pandemic, remote monitoring was performed in place of follow-up visits scheduled but not provided, or in addition to them, according to the clinical needs of our patients, especially with quiescent, mild, or moderate disease. Prescription sheets were also provided via e-mail. Patients received a phone call at least three days before the scheduled consultation asking their consent for e-mail consultation; if they agreed, they were asked to send by email, within the scheduled date or the day after, results of blood tests and a summary of their clinical status (all the patients in follow-up in our IBD clinic receive a note reporting clinical history, information about disease activity, therapy prescription, and the invitation for the next appointment with a list of blood tests). Questionnaires were also sent for an objective evaluation of the disease. Doctors provided, by email within the same day or the day after, new prescriptions if necessary or the date for next appointment. Though an asynchronous process, clinical notes were updated. Patients with severe active disease were invited to the clinic. The decision to go to the emergency room was up to the patients. In fact, F2F visits were performed as usual in patients with severe disease or emergencies, and urgent hospitalizations of patients coming to the emergency room were guaranteed as usual. The number of the patients represents all the patients scheduled for follow-up visits in the study period. Moreover, patients on biologics were allowed face-to-face visits both if on subcutaneous biologics and if on intravenous drugs. All patients were asked to complete a questionnaire, submitted through e-mail, focusing on the following elements of the intervention: (1) self-assessment questions, (2) action plans, and (3) educational messages. With regard to self-assessment questions, we used the SIBDQ [17] (to evaluate the QoL) and the IBDSI [18] (to evaluate symptoms as patients' reported outcomes, see Supplementary Tables S2 and S3). All patients sent by e-mail the results of blood tests: Erythrocyte Sedimentation Rate (ESR), C-Reactive Protein (CRP), complete blood count 
(CBC), faecal calprotectin, ferritin, and serum iron. Harvey Bradshaw Index [19] and Mayo Ulcerative Colitis [20] scores were calculated by the treating physicians.

The results of our survey are reported according to Cherries checklist (see Supplementary Table S1), a list of recommendations formulated in order to ensure complete descriptions of e-survey methodology. This checklist, though mainly focused on web-based surveys, is valid also for e-mail administered surveys [21].

\section{Statistical Analysis}

Descriptive analysis was carried out by calculating mean and standard deviation for continuous variables and proportions for categorical variables.

The comparison of linked samples was performed using the two-tailed nonparametric Wilcoxon test. A $p$ value of less than 0.05 was considered to indicate statistical significance.

We used univariate and multivariable logistic regression analysis to identify risk factors from possible variables for the following outcomes: patients' satisfaction about the use of telemedicine, positive influence of telemedicine in $\mathrm{QoL}$, and necessity for treatment change, defined as a treatment escalation with regard to the standard of care.

The univariate model used independent variables related to patient and procedure characteristics. Crude odds ratios (ORs) and their $95 \%$ confidence intervals (CIs) were calculated. Any factors associated with the outcome with $p<0.05$ on univariate analysis were entered into a multivariable logistic regression analysis to determine any independent predictors of the outcome. Adjusted ORs and their $95 \%$ CIs were obtained from multiple logistic regression model.

All analyses were performed using the SPSS software (IBM Corp. Released 2017. IBM SPSS Statistics for Windows, Version 25.0. Armonk, NY, USA: IBM Corp).

\section{Results}

The patients' baseline characteristics are described in Table 1.

Table 1. Baseline characteristics of patients.

\begin{tabular}{|c|c|c|c|}
\hline Characteristic & $\mathrm{CD}(n=220)$ & $\mathrm{UC}(n=189)$ & $\begin{array}{c}\text { Unclassified } \\
\text { Colitis }(n=14)\end{array}$ \\
\hline Age, years (median, IQR) & $48(33-60)$ & $50(35-62)$ & $35(25-50)$ \\
\hline Male, $n(\%)$ & $122(55.5)$ & $101(53.4)$ & $10(71.4)$ \\
\hline \multicolumn{4}{|l|}{ Disease location (CD) } \\
\hline Ileum only & $88(41.9)$ & & \\
\hline Ileum and colon & $116(55.2)$ & & \\
\hline Colon only & $6(2.9)$ & & \\
\hline \multicolumn{4}{|l|}{ Disease location (UC) } \\
\hline Proctitis & & $38(22.2)$ & \\
\hline Proctosigmoiditis & & $59(34.5)$ & \\
\hline Left sided colitis & & $26(15.2)$ & \\
\hline Pancolitis & & $48(28.1)$ & \\
\hline Disease duration (mean, SD) & $9.6(8.4)$ & $9.1(7.1)$ & $5.2(3.2)$ \\
\hline HBI for CD (median, IQR) & $2(1-4)$ & & \\
\hline Mayo score for UC (median, IQR) & & $2(1-3)$ & \\
\hline C-reactive protein (median, IQR) & $2.5(0.6-6.0)$ & $1.4(0.5-4.2)$ & $0.95(0.8-2.0)$ \\
\hline $\begin{array}{c}\text { Erithrocyte sedimentation rate } \\
\text { (median, IQR) }\end{array}$ & $12.0(5.3-25.0)$ & $13(5.0-21.0)$ & $6(4-12)$ \\
\hline Albumin (median, IQR) & $4.0(3.8-4.4)$ & $4.0(3.9-4.2)$ & $4.0(3.8-4.4)$ \\
\hline Blood iron level (median, IQR) & $73.0(47.8-91.5)$ & $75(56.8-96.5)$ & $78(52.3-82.8)$ \\
\hline Serum ferritin (median, IQR) & $54(25.8-115.5)$ & $50.5(23.0-113.0)$ & $40.5(10.2-84.0)$ \\
\hline Haemoglobin (median, IQR) & $12.8(9.9-14.1)$ & $12.8(10.3-14.4)$ & $14.0(13.4-14.7)$ \\
\hline $\begin{array}{l}\text { White blood cell count } \\
\text { (median, IQR) }\end{array}$ & $\begin{array}{c}6700 \\
(5415-8300)\end{array}$ & $\begin{array}{c}6780 \\
(5610-8535)\end{array}$ & $6400(5682-8870)$ \\
\hline
\end{tabular}


Interestingly, 410 (96.9\%) patients were satisfied with telemedicine, and 320 (76.5\%) patients answered that they would maintain this approach after the COVID-19 outbreak, also.

The patients' replies to the questionnaires are described in Tables 2 and 3.

Table 2. Univariate logistic regression analysis evaluating predictors of improved QoL in CD.

\begin{tabular}{cccc}
\hline Quality of Life & Odds Ratio & $\begin{array}{c}\text { 95\% Confidence } \\
\text { Interval }\end{array}$ & $p$-Value \\
\hline Age, years & 1.01 & $0.98-1.04$ & 0.697 \\
Male sex & 0.45 & $0.18-1.14$ & 0.094 \\
Disease location & & & 0.853 \\
Ileum and colon & 1.09 & $0.44-2.71$ & $\mathbf{0 . 0 4 2}$ \\
Disease duration & $\mathbf{1 . 0 5}$ & $\mathbf{1 . 0 0 - 1 . 1 1}$ & 0.404 \\
Harvey-Bradshaw index & 1.05 & $0.93-1.19$ & 0.986 \\
C-reactive protein & 1.00 & $0.95-1.06$ & 0.773 \\
Erithrocyte & 1.00 & $0.98-1.03$ & 0.245 \\
sedimentation rate & 0.49 & $0.15-1.64$ & 0.439 \\
Albumin & 0.99 & $0.98-1.01$ & 0.855 \\
Blood iron level & 0.99 & $0.99-1.01$ & 0.842 \\
Serum ferritin & 1.00 & $0.99-1.01$ & 0.421 \\
Haemoglobin & 0.99 & $0.99-1.00$ & \\
\hline White blood cell count & & & \\
\hline
\end{tabular}

Table 3. Univariate logistic regression analysis evaluating predictors of improved CD patient's satisfaction about telemedicine.

\begin{tabular}{cccc}
\hline Satisfaction & Odds Ratio & $\begin{array}{c}\text { 95\% Confidence } \\
\text { Interval }\end{array}$ & $p$-Value \\
\hline Age, years & 0.99 & $0.97-1.02$ & 0.594 \\
Male sex & 1.46 & $0.77-2.78$ & 0.245 \\
Disease location & & & \\
Ileum and colon & $\mathbf{0 . 5 2}$ & $\mathbf{0 . 2 7 - 0 . 9 9}$ & $\mathbf{0 . 0 4 8}$ \\
Disease duration & 1.03 & $0.99-1.07$ & 0.211 \\
Harvey-Bradshaw index & $\mathbf{0 . 8 1}$ & $\mathbf{0 . 6 7 - 0 . 9 9}$ & $\mathbf{0 . 0 3 7}$ \\
C-reactive protein & $\mathbf{0 . 8 4}$ & $\mathbf{0 . 7 5 - 0 . 9 4}$ & $\mathbf{0 . 0 3 0}$ \\
Erithrocyte sedimentation rate & $\mathbf{0 . 9 5}$ & $\mathbf{0 . 9 2 - 0 . 9 8}$ & $\mathbf{0 . 0 2 0}$ \\
Albumin & 0.99 & $0.98-1.01$ & 0.546 \\
Blood iron level & $\mathbf{1 . 0 1}$ & $\mathbf{1 . 0 0 - 1 . 0 2}$ & $\mathbf{0 . 0 3 4}$ \\
Serum ferritin & 0.99 & $0.99-1.00$ & 0.660 \\
Haemoglobin & 1.00 & $0.99-1.01$ & 0.672 \\
White blood cell count & 0.99 & $0.99-1.00$ & 0.160 \\
\hline
\end{tabular}

From 52.4 to $96.6 \%$ of patients reported to have no bowel symptoms, whereas the percentage of patients who reported having no fatigue and no complications was 76.1-97.3\% and 76.5-98.5\%, respectively. Regarding the SIBQD questionnaire, 60.7-81.0 per cent of patients reported having a satisfactory QoL.

Overall, upon univariate logistic regression analysis, none of the variables was related to patients' satisfaction and to an improved QoL. The presence of ulcerative colitis (OR 1.91, CI1.01-3.61, $p=0.043$ ) was associated with the need for treatment change, defined as a treatment escalation with regard to the standard of care. Therefore, multivariate analysis was not carried out.

In CD patients, on univariate logistic analysis, a shorter disease duration (OR 1.05, IC 1.00-1.11, $p=0.042$ ) was associated with an improved QoL. An ileocolonic localization (OR 0.52, CI 0.27-0.99, $p=0.048$ ), a lower Harvey Bradshaw Index (OR 0.81, CI 0.67-0.99, $p=0.037$ ), a lower C-reactive protein (OR0.84, CI 0.75-0.94, $p=0.003$ ), a lower erythrocyte sedimentation rate (OR 0.95, CI 0.92-0.98, $p=0.002$ ), and a higher blood iron level (OR $1.01, \mathrm{CI} 1.00-1.00, p=0.034)$ were associated with patient's satisfaction. Such variables entered a multivariate logistic regression model which showed that there was a trend 
toward statistical significance for the association between the ileocolonic localization (OR 0.048, CI 0.22-1.06, $p=0.071$ ), a lower C-reactive protein (OR 0.89, CI 0.78-1.01, $p=0.075$ ), and a lower erythrocyte sedimentation rate (OR 0.97, CI 0.94-1.00, $p=0.073$ ) with the aforementioned outcome.

In UC patients, on univariate logistic analysis, a lower white blood cell count was associated with an improved QoL (OR 1.00, CI 1.00-1.01, $p=0.038$ ), whereas a lower erythrocyte sedimentation rate (OR 1.02, CI 1.00-1.04, $p=0.022$ ) and a lower white blood cell count (OR 1.01, CI 1.00-1.02, $p=0.021$ ) were associated with patients' satisfaction, and a higher Mayo score (OR 1.57, CI 1.24-1.98, $p<0.001$ ) was associated with need for treatment change, defined as a treatment escalation with regard to the standard of care. None of the variables were significant on multivariate analysis and, therefore, multivariate logistic regression analysis was not carried out (see Tables 4-10).

Table 4. Multivariate logistic regression analysis evaluating predictors of improved CD patient's satisfaction about telemedicine.

\begin{tabular}{cccc}
\hline Satisfaction & Odds Ratio & 95\% Confidence Interval & $p$-Value \\
\hline Disease location & & & 0.071 \\
Ileum and colon & 0.48 & $0.22-1.06$ & 0.199 \\
Harvey-Bradshawindex & 0.86 & $0.67-1.09$ & 0.075 \\
C-reactiveprotein & 0.89 & $0.78-1.01$ & 0.073 \\
Erithrocytesedimentation rate & 0.97 & $0.94-1.00$ & 0.194 \\
Blood ironlevel & 1.01 & $0.99-1.02$ & \\
\hline
\end{tabular}

Table 5. Univariate logistic regression analysis evaluating predictors of improved QoL in UC.

\begin{tabular}{cccc}
\hline Quality of Life & Odds Ratio & $\mathbf{9 5 \%}$ Confidence Interval & $p$-Value \\
\hline Age, years & 1.02 & $0.99-1.05$ & 0.237 \\
Male sex & 0.87 & $0.29-2.59$ & 0.804 \\
Disease location & 0.40 & $0.09-1.85$ & 0.240 \\
Pancolitis & 1.03 & $0.96-1.11$ & 0.452 \\
Diseaseduration & 1.20 & $0.90-1.60$ & 0.207 \\
Mayo score & 0.99 & $0.93-1.07$ & 0.910 \\
C-reactiveprotein & 1.01 & $0.99-1.04$ & 0.324 \\
Erithrocytesedimentation rate & 0.92 & $0.45-1.88$ & 0.819 \\
Albumin & 0.99 & $0.97-1.01$ & 0.496 \\
Blood ironlevel & 1.00 & $0.99-1.01$ & 0.534 \\
Serumferritin & 0.99 & $0.98-1.01$ & 0.763 \\
Haemoglobin & 1.00 & $1.00-1.01$ & 0.038 \\
White bloodcellcount & & & \\
\hline
\end{tabular}

Table 6. Univariate logistic regression analysis evaluating predictors of improved UC patient's satisfaction about telemedicine.

\begin{tabular}{cccc}
\hline Satisfaction (UC) & Odds Ratio & $\mathbf{9 5 \%}$ & $p$-Value \\
\hline Age, years & 1.00 & $0.98-1.02$ & 0.806 \\
Male sex & 0.79 & $0.41-1.52$ & 0.476 \\
Disease location & & & 0.198 \\
Pancolitis & 0.57 & $0.24-1.34$ & 0.219 \\
Diseaseduration & 1.03 & $0.98-1.08$ & 0.062 \\
Mayo score & 0.78 & $0.61-1.01$ & 0212 \\
C-reactiveprotein & 1.02 & $0.99-1.06$ & $\mathbf{0 . 0 2 2}$ \\
Erithrocytesedimentation rate & $\mathbf{1 . 0 2}$ & $\mathbf{1 . 0 0 - 1 . 0 4}$ & 0.521 \\
Albumin & 0.74 & $0.30-1.83$ & 0.166 \\
Blood ironlevel & 0.99 & $0.98-1.00$ & 0.392 \\
Serumferritin & 0.99 & $0.99-1.00$ & 0.256 \\
Haemoglobin & 0.99 & $\mathbf{1 . 0 0 - 1 . 0 2}$ & $\mathbf{0 . 0 2 1}$ \\
White blood cell count & $\mathbf{1 . 0 1}$ & & \\
\hline
\end{tabular}


Table 7. Univariate logistic regression analysis evaluating predictors for change of treatment in UC patients.

\begin{tabular}{cccc}
\hline Treatment Change & Odds Ratio & $\mathbf{9 5 \%}$ Confidence Interval & $p$-Value \\
\hline Age, years & 0.98 & $0.96-1.01$ & 0.151 \\
Male sex & 0.85 & $0.37-1.95$ & 0.705 \\
Disease location & & & 0.065 \\
Pancolitis & 0.31 & $0.09-1.08$ & 0.291 \\
Disease duration & 0.96 & $0.89-1.03$ & $<0.001$ \\
Mayo score & $\mathbf{1 . 5 7}$ & $\mathbf{1 . 2 4 - 1 . 9 8}$ & 0.832 \\
C-reactiveprotein & 1.00 & $0.96-1.05$ & 0.330 \\
Erithrocyte sedimentation rate & 1.01 & $0.99-1.03$ & 0.674 \\
Albumin & 0.79 & $0.26-2.39$ & 0.265 \\
Blood iron level & 0.99 & $0.97-1.01$ & 0.111 \\
Serumferritin & 1.00 & $0.99-1.01$ & 0.389 \\
Haemoglobin & 0.99 & $0.98-1.00$ & 0.057 \\
White bloodcellcount & 1.00 & $0.99-1.01$ & \\
\hline
\end{tabular}

Table 8. Univariate logistic regression analysis evaluating predictors of improved QoL in the whole population.

\begin{tabular}{cccc}
\hline Quality of Life & Odds Ratio & $\mathbf{9 5 \%}$ Confidence Interval & $p$-Value \\
\hline Age, years & 1.01 & $0.99-1.03$ & 0.491 \\
Male sex & 0.66 & $0.34-1.31$ & 0.238 \\
Type of IBD & & & 0.541 \\
UC & 0.83 & $0.45-1.53$ & 0.984 \\
Disease location & 0.99 & $0.49-2.00$ & \\
Extensive (pancolitis for CUR; & & & 0.509 \\
ileocolic for Crohn) & 0.99 & $0.98-1.00$ & 0.996 \\
Diseaseduration & 1.00 & $0.96-1.04$ & 0.434 \\
C-reactiveprotein & 1.01 & $0.99-1.02$ & 0.502 \\
Erithrocytesedimentation rate & 0.74 & $0.31-1.79$ & 0.320 \\
Albumin & 0.99 & $0.98-1.01$ & 0.805 \\
Blood ironlevel & 1.00 & $0.99-1.01$ & $0.99-1.01$ \\
Serumferritin & 1.00 & $0.99-1.01$ & 0.693 \\
Haemoglobin & 1.00 & & \\
White blood cell count & & & \\
\hline
\end{tabular}

Table 9. Univariate logistic regression analysis evaluating predictors of improved patient's satisfaction about telemedicine in the whole population.

\begin{tabular}{cccc}
\hline Satisfaction & Odds Ratio & 95\% Confidence Interval & $p$-Value \\
\hline Age, years & 0.99 & $0.98-1.01$ & 0.564 \\
Male sex & 1.12 & $0.71-1.75$ & 0.623 \\
Type of IBD & 1.05 & $0.67-1.64$ & 0.823 \\
CU & & & 0.592 \\
Disease location & 0.94 & $0.74-1.20$ & 0.505 \\
Extensive (pancolitis for CUR; ileocolic for Crohn) & & & 0.370 \\
Diseaseduration & 1.00 & $0.99-1.00$ & 0.259 \\
C-reactiveprotein & 0.99 & $0.95-1.02$ & 0.489 \\
Erithrocytesedimentation rate & 0.99 & $0.98-1.01$ & 0.383 \\
$\quad$ Albumin & 0.99 & $0.97-1.01$ & 0.382 \\
Blood ironlevel & 1.00 & $0.99-1.01$ & 0.66 \\
Serumferritin & 0.99 & $0.99-1.00$ & $0.99-1.00$ \\
Haemoglobin & 0.99 & $0.99-1.01$ & 0.963 \\
White bloodcellcount & 1.00 & & \\
\hline
\end{tabular}


Table 10. Univariate logistic regression analysis evaluating predictors for change of treatment in the whole population.

\begin{tabular}{cccc}
\hline Change Treatment (Overall) & Odds Ratio & 95\% Confidenceinterval & $p$-Value \\
\hline Age, years & 0.98 & $0.96-1.00$ & 0.063 \\
$\quad$ Male sex & 0.87 & $0.47-1.64$ & 0.679 \\
Type of IBD & $\mathbf{1 . 9 1}$ & $\mathbf{1 . 0 1 - 3 . 6 1}$ & $\mathbf{0 . 0 4 3}$ \\
$\quad$ CU & & & $0.77-1.37$ \\
Disease location & 1.03 & & 0.834 \\
Extensive (pancolitis for CUR; ileocolic for Crohn) & & $0.99-1.00$ & 0.763 \\
Diseaseduration & 0.99 & $0.96-1.04$ & 0.934 \\
C-reactiveprotein & 0.99 & & 0.313 \\
Erithrocytesedimentation rate & & $0.34-1.50$ & 0.122 \\
$\quad$ Albumin & 0.65 & $0.98-1.00$ & 0.789 \\
Blood ironlevel & 0.99 & $0.99-1.00$ & $0.99-1.01$ \\
Serumferritin & 1.00 & $0.99-1.01$ & 0.061 \\
Haemoglobin & 0.99 & 1.00 & \\
White blood cell count & &
\end{tabular}

\section{Discussion}

Though telemedicine tools have been investigated in the past in gastroenterology and hepatology in the management of patients with chronic disease (IBD, HCV infection) [21,22] with conflicting results, COVID-19 provided a unique opportunity for implementation of novel technologies in clinical practice and induced healthcare institutions, gastroenterologists, and patients to use online platforms to safely access healthcare without delays in medical interventions [21].

As far as IBD is concerned, platforms such as IBD QorusTM program centers [23], Health PROMISE [24], IBD LIVETM (Liver Interinstitutional and interdisciplinary Video conference Education) [25], and myIBDcoach [26] have been developed in order to provide high-quality care, improve adherence to treatment regimens, and identify disease progression at early stages facilitating the timely institution of therapies [21].

Indeed, telemedicine could be utilized in these patients to provide appropriate medication adjustments (initiation of biological therapy, use of corticosteroids or add on of topical therapy in case of exacerbations) according to patients', needs without waiting for scheduled follow-up visits.

In our study, we used remote monitoring to assess patients' health status, quality of life, and perception about telemedicine.

To date, only a few studies have investigated the role of telemedicine in IBD during the SARS-CoV2 outbreak [27-29].

Our study shows some strengths but also some points of weakness.

The main points of strength of our study are: the prospective collections of patients' data, the findings regarding the association of patients' perceptions and satisfaction with the baseline patients features themselves, and the collection, in the questionnaire, of patients' reported outcome (PRO) through the use of SIBDQ and IBDSI in order to assess objectively patient's health status.

To our knowledge, our study is the only one that has demonstrated that telemedicine during the pandemics has not worsened clinical outcomes, while it potentially has helped in reducing the spreading of the contagion limiting the access to the hospital. This is a valuable result, though it must be noted that the majority of our population was in clinical remission and have a satisfactory QoL.

The present study has also some limitations. First: too few patients had unclassified colitis and, due to this reason, we did not perform logistic regression analysis in order to assess the factor associated with patients' satisfaction, QoL, and need for treatment change. Secondly, data about fecal calprotectin were not available in almost all of the patients. The integration of clinical symptoms as PRO with fecal calprotectin could have provided a 
better insight into disease activity. Indeed, a point-of-care fecal calprotectin test has been developed to be included in self-assessment tools, though it has not been commercially diffused in many countries [30]. Third, the follow-up of our patients was short; this could lead to a selection bias because many IBD patients on stable maintenance therapy may relapse in a wider interval of time; however, the period identified the status of our cohort of IBD patients during the first lockdown in Italy. Moreover, we did not assess the impact of socioeconomic and educational status on the acceptance of telemedicine, though most of the patients followed up in our clinic have a low income and live in rural areas with presumably limited access to technology. Remote monitoring could also affect medication adherence, but this has not been addressed in our study.

Last, but not least, with regard to the design of the study, we do not have a control group. However, our results are in keeping with those of McCombie and coworkers, who performed a non-inferiority randomized Clinical Trial of the Use of the Smartphone-Based Health Applications in IBD patients, showing that remote symptom and fecal calprotectin monitoring results are effective and acceptable, and that patients with mild-to-moderate disease, who are not new diagnoses, are ideal for this system [31].

In conclusion, our results suggest, in a homogeneous cohort of IBD patients, that a telemedicine approach could replace in-person consultations, at least for patients in remission or with mild clinical activity. Although e-mail is a basic form of teleconsultation, this study supports its use. This approach was also safe, since a significant increase in referral to emergency departments or steroid use for disease flare was not observed. The first is particularly relevant, since the access to emergency rooms is a marker of bad quality of care in a patient-centered structured approach to the care of chronic disease provided by certified referral centers. A high proportion of patients were satisfied and would maintain remote monitoring; patients with IBD seem to have a good perception of telemedicine, as suggested by other studies, even if with conflicting results [32,33], and this attitude is not limited to the youngest and so-called "digital native" patients. Telemedicine could be the COVID-19 legacy in the management of IBD, aiming to reduce the cost of patients' care and rationalize the use of health resources with the standardization of infrastructures and costs [34,35]. Moreover, IBDs are heterogeneous diseases, with about half of the patients experiencing a mild disease, while $20-30 \%$ of patients develop an aggressive course: telemedicine can maintain an adequate follow-up and a satisfying patient-doctor relationship while traditional consultations are provided to severe disease and to recent-onset disease, where talking with the doctor in person is a more effective way of providing health care (need of physical examination, of point-of-care texts such as ultrasound, empathy with the doctor). The COVID-19 pandemic has fueled the interest of health authorities in telemedicine: this will allow overcoming some of the barriers to the implementation of telemedicine such as reimbursement and legal liability issues. The development of more advanced platforms of telemedicine with a strict observance of GDPR (general data protection regulation) and cybersecurity rules is also warranted. Although initial investments in resources, software, training, and maintenance will be necessary at the beginning, telemedicine is going to be, in the long term, helpful for health organizations to reduce the burden associated with IBD [34-36].

Disclosures: MC has served as speaker and advisory board member for Takeda, Janssen, Fresenius, Celltrion. Ciro Celsa received speaker fees from Eisai. The other authors declares that they have no relevant or material financial interests that relate to the research described in this paper.

Supplementary Materials: The following supporting information can be downloaded at: https:/ / www.mdpi.com/article/10.3390/gastroent13010013/s1, Table S1: Cherries Checklist for Web Surveys; Table S2: Short Infammatory Bowel Disease Questionnaire (SIBDQ) in our population; Table S3: IBD Symptom Inventory (IBDSI)—Long Form in our population. 


\begin{abstract}
Author Contributions: Conceptualization, E.S., C.C. (Calogero Cammà) and M.C.; methodology, C.C. (Ciro Celsa), S.B., M.M. and C.C. (Calogero Cammà); data curation, A.B., L.G., L.C., F.C. and D.B.; writing-original draft preparation, E.S., M.M., A.B. and M.C.; editing, C.C. (Ciro Celsa) and M.C.; supervision, M.C. and C.C. (Calogero Cammà). All authors have read and agreed to the published version of the manuscript.
\end{abstract}

Funding: This research received no external funding.

Institutional Review Board Statement: Ethical review and approval were waived for this study, due to the fact that this was only a survey on IBD patients submitted to remote monitoring.

Informed Consent Statement: Not applicable.

Data Availability Statement: Not applicable.

Conflicts of Interest: MC has served as speaker and advisory board member for Takeda, Janssen, Fresenius, Celltrion. Ciro Celsa received speaker fees from Eisai. The other authors declares that they have no relevant or material financial interests that relate to the research described in this paper.

\title{
References
}

1. Orlando, A.; Guglielmi, F.W.; Cottone, M.; Orlando, E.; Romano, C.; Sinagra, E. Clinical implications of mucosal healing in the management of patients with inflammatory bowel disease. Dig. Liver Dis. 2013, 45, 986-991. [CrossRef] [PubMed]

2. Abraham, C.; Cho, J.H. Inflammatory Bowel Disease. N. Engl. J. Med. 2009, 361, 2066-2078. [CrossRef] [PubMed]

3. Jairath, V.; Feagan, B.G. Global burden of inflammatory bowel disease. Lancet Gastroenterol. Hepatol. 2020, 5, 2-3. [CrossRef]

4. George, L.A.; Cross, R.K. Remote monitoring and telemedicine in IBD: Are we there yet? Curr. Gastroenterol. Rep. 2020, $22,12$. [CrossRef]

5. Telehealth Basics. American Telemedicine Association. Available online: https://www.americantelemed.org/resource/whytelemedicine/ (accessed on 15 June 2021).

6. Perisetti, A.; Goyal, H. Successful distancing: Telemedicine in gastroenterology and hepatology during the COVID-19 pandemic. Dig. Dis. Sci. 2021, 66, 945-953. [CrossRef]

7. Cross, R.K.; Cheevers, N.; Rustgi, A.; Langenberg, P.; Finkelstein, J. Randomized, controlled trial of home telemanagement in patients with ulcerative colitis (UC HAT). Inflamm. Bowel Dis. 2012, 18, 1018-1025. [CrossRef]

8. Elkjaer, M.; Shuhaibar, M.; Burisch, J.; Bailey, Y.; Scherfig, H.; Laugesen, B.; Avnstrøm, S.; Langholz, E.; O’Morain, C.; Lynge, E.; et al. E-health empowers patients with ulcerative colitis: A randomised controlled trial of the web-guided 'Constant-care' approach. Gut 2010, 59, 1652-1661. [CrossRef]

9. Spiegel, B. 2015 American journal of gastroenterology lecture: How digital health will transform gastroenterology. Am. J. Gastroenterol. 2016, 111, 624-630. [CrossRef]

10. Serper, M.; Cubell, A.W.; Deleener, M.E.; Casher, T.K.; Rosenberg, D.J.; Whitebloom, D.; Rosin, R.M. Telemedicine in Liver Disease and Beyond: Can the COVID-19 Crisis Lead to Action? Hepatology 2020, 72, 723-728. [CrossRef]

11. Hollander, J.E.; Carr, B.G. Virtually perfect? Telemedicine for COVID-19. N. Engl. J. Med. 2020, 382, 1679-1681. [CrossRef]

12. Perisetti, A.; Gajendran, M.; Boregowda, U.; Bansal, P.; Goyal, H. COVID-19 and gastrointestinal endoscopies: Current insights and emergent strategies. Dig. Endosc. 2020, 32, 715-722. [CrossRef] [PubMed]

13. Perisetti, A.; Goyal, H.; Gajendran, M.; Boregowda, U.; Mann, R.; Sharma, N. Prevalence, mechanisms, and implications of gastrointestinal symptoms in COVID-19. Front. Med. 2020, 7, 588711. [CrossRef] [PubMed]

14. Repici, A.; Maselli, R.; Colombo, M.; Gabbiadini, R.; Spadaccini, M.; Anderloni, A.; Carrara, S.; Fugazza, A.; Di Leo, M.; Galtieri, P.A.; et al. Coronavirus (COVID-19) outbreak: What the department of endoscopy should know. Gastrointest. Endosc. 2020, 92, 192-197. [CrossRef] [PubMed]

15. Costantino, A.; Noviello, D.; Mazza, S.; Berté, R.; Caprioli, F.; Vecchi, M. Trust in telemedicine from IBD outpatients during the COVID-19 pandemic. Dig. Liver Dis. 2021, 53, 291-294. [CrossRef]

16. Available online: https://ecco-ibd.eu/images/6_Publication/6_8_Surveys/2nd_Interview_COVID-19_ECCO_Taskforce_ published.pdf (accessed on 16 February 2022).

17. Irvine, E.J.; Zhou, Q.; Thompson, A.K. The Short Inflammatory Bowel Disease Questionnaire: A quality of life instrument for community physicians managing inflammatory bowel disease. CCRPT Investigators. Canadian Crohn's Relapse Prevention Trial. Am. J. Gastroenterol. 1996, 91, 1571-1578.

18. Sexton, K.A.; Walker, J.R.; Targownik, L.E.; Graff, L.A.; Haviva, C.; Beatie, B.; Petty, S.K.; Bernstein, M.T.; Singh, H.; Miller, N.; et al. The inflammatory bowel disease symptom inventory: A patient-report scale for research and clinical application. Inflamm. Bowel Dis. 2019, 25, 1277-1290. [CrossRef]

19. Harvey, R.; Bradshaw, J. A simple index of Crohn's-disease activity. Lancet 1980, 315, 514. [CrossRef]

20. Schroeder, K.W.; Tremaine, W.J.; Ilstrup, D.M. Coated oral 5-aminosalicylic acid therapy for mildly to moderately active ulcerative colitis. N. Engl. J. Med. 1987, 317, 1625-1629. [CrossRef] 
21. Eysenbach, G. Improving the quality of Web surveys: The checklist for reporting results of internet E-Surveys (cherries). J. Med. Internet Res. 2004, 6, e34. [CrossRef]

22. George, L.A.; Cross, R.K. Telemedicine in gastroenterology in the wake of COVID-19. Expert Rev. Gastroenterol. Hepatol. 2020, 14, 1013-1015. [CrossRef]

23. Cross, R.K.; Kane, S. Integration of telemedicine into clinical gastroenterology and hepatology practice. Clin. Gastroenterol. Hepatol. 2017, 15, 175-181. [CrossRef] [PubMed]

24. Johnson, L.; Melmed, G.Y.; Nelson, E.C.; Holthoff, M.M.; Weaver, A.S.; Morgan, T.S.; Siegel, C.A. Fostering collaboration through creation of an IBD learning health system. Am. J. Gastroenterol. 2017, 112, 406-408. [CrossRef] [PubMed]

25. Atreja, A.; Khan, S.; Rogers, J.D.; Otobo, E.; Patel, N.P.; Ullman, T.; Colombel, J.F.; Moore, S.; Sands, B.E. Impact of the mobile Health PROMISE platform on the quality of care and quality of life in patients with infammatory bowel disease: Study protocol of a pragmatic randomized controlled trial. JMIR Res. Protoc. 2015, 4, e23. [CrossRef] [PubMed]

26. Regueiro, M.D.; Greer, J.B.; Binion, D.G.; Schraut, W.H.; Goyal, A.; Keljo, D.J.; Cross, R.K.; Williams, E.D.; Herfarth, H.H.; Siegel, C.A.; et al. The inflammatory bowel disease live interinstitutional and interdisciplinary videoconference education (IBD LIVE) series. Inflamm. Bowel Dis. 2014, 20, 1687-1695. [CrossRef]

27. de Jong, M.J.; Boonen, A.; Jong, A.E.V.D.M.-D.; Romberg-Camps, M.J.; van Bodegraven, A.A.; Mahmmod, N.; Markus, T.; Dijkstra, G.; Winkens, B.; van Tubergen, A.; et al. Cost-effectiveness of Telemedicine-directed Specialized vs. Standard Care for Patients With Inflammatory Bowel Diseases in a Randomized Trial. Clin. Gastroenterol. Hepatol. 2020, 18, 1744-1752. [CrossRef]

28. Lees, C.W.; Regueiro, M.; Mahadevan, U. Innovation in inflammatory bowel disease care during the COVID-19 pandemic: Results of a global telemedicine survey by the international organization for the study of inflammatory bowel disease. Gastroenterol 2020, 159, 805-808.e1. [CrossRef]

29. Zingone, F.; Siniscalchi, M.; Savarino, E.V.; Barberio, B.; Cingolani, L.; D’Incà, R.; De Filippo, F.R.; Camera, S.; Ciacci, C. Perception of the COVID-19 pandemic among patients with inflammatory bowel disease in the time of telemedicine: Cross-Sectional questionnaire study. J. Med. Internet Res. 2020, 22, e19574. [CrossRef]

30. van Velsen, L.; Tabak, M.; Hermens, H. Measuring patient trust in telemedicine services: Development of a survey instrument and its validation for an anticoagulation web-service. Int. J. Med. Inform. 2017, 97, 52-58. [CrossRef]

31. Haisma, S.M.; Galaurchi, A.; Almahwzi, S.; Adekanmi Balogun, J.A.; Muller Kobold, A.C.; van Rheenen, P.F. Head-to-head comparison of three stool calprotectin tests for home use. PLOS ONE 2019, 14, e0214751. [CrossRef]

32. McCombie, A.; Walmsley, R.; Barclay, M.; Ho, C.; Langlotz, T.; Regenbrecht, H.; Gray, A.; Visesio, N.; Inns, S.; Schultz, M. A noninferiority randomized clinical trial of the use of the smartphone-based health applications IBDsmart and IBDoc in the care of inflammatory bowel disease patients. Inflamm. Bowel Dis. 2020, 26, 1098-1109. [CrossRef]

33. Barsom, E.Z.; Jansen, M.; Tanis, P.; van de Ven, A.W.H.; van Oud-Alblas, M.B.; Buskens, C.J.; Bemelman, W.A.; Schijven, M.P. Video consultation during follow up care: Effect on quality of care and patient- and provider attitude in patients with colorectal cancer. Surg. Endosc. 2021, 35, 1278-1287. [CrossRef] [PubMed]

34. Schliep, M.; Chudy-Onwugaje, K.; Abutaleb, A.; Langenberg, P.; Regueiro, M.; Schwartz, D.A.; Tracy, J.K.; Ghazi, L.; Patil, S.A.; Quezada, S.; et al. TELEmedicine for patients with inflammatory bowel disease (TELE-IBD) does not improve depressive symptoms or general quality of life compared with standard care at tertiary referral centers. Crohns Colitis 2020, 360, 2. [CrossRef] [PubMed]

35. Gallo, G.; Grossi, U.; Sturiale, A.; Di Tanna, G.L.; Picciariello, A.; Pillon, S.; Mascagni, D.; Altomare, D.F.; Naldini, G.; Perinotti, R.; et al. E-consensus on telemedicine in proctology: A RAND/UCLA-modified study. Surgery 2021, 170, 405-411. [CrossRef] [PubMed]

36. Gallo, G.; Picciariello, A.; Di Tanna, G.L.; Santoro, G.A.; Perinotti, R.; Aiello, D.; Avanzolini, A.; Balestra, F.; Bianco, F.; Binda G.A.; et al. E-consensus on telemedicine in colorectal surgery: A RAND/UCLA-modified study. Updat. Surg. 2022, 74, 163-170, Erratum in Updat. Surg. 2021, 74, 163-170. [CrossRef] 